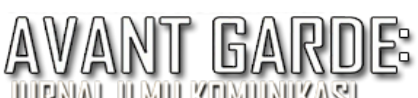

\title{
Personal Branding Vegan Influencer di Instagram
}

\author{
Viendra Salsabila, Hanny Hafiar, Diah Fatma Sjoraida \\ beby.viendra@gmail.com; hannyhafiar@gmail.com \\ Universitas Padjadjaran, Jl. Raya Bandung Sumedang KM.21, Kabupaten Sumedang, Indonesia
}

Submitted: 12 Juni 2021, Revised: 16 Juni 2021, Accepted : 16 Juni 2021

\begin{abstract}
Abstrak
Indonesia adalah negara ke-16 terbaik untuk hidup dengan gaya hidup vegan. Walau begitu, jumlah penduduk vegan di Indonesia jumlahnya masih sedikit. Penelitian ini bertujuan untuk mengetahui pemaknaan vegan bagi vegan influencer, motif vegan influencer dalam membangun personal branding di Instagram, dan pengalaman komunikasi vegan influencer dalam membangun personal branding di Instgaram. Teori yang digunakan dalam penelitian ini adalah Teori Fenomenologi Schutz dan Teori Interaksi Simbolik oleh George Herbert Mead. Penelitian ini menggunakan metode fenomenologi dan paradigma konstruktivisme. Hasil penelitian pada 10 informan menunjukkan bahwa vegan influencer memaknai vegan sebagai dan untuk kesehatan, lingkungan, etika, dan makanan. Motif vegan influencer dikategorikan menjadi 2 kategori, pertama because-motive dan inorder-to-motives. Pengalaman komunikasi vegan influencer dalam membangun personal branding di Instagram dibagi menjadi dua, yaitu pengalaman komunikasi saat awal menjadi vegan influencer di Instagram dan setelah menjadi vegan influencer di Instagram. Saran yang dapat diberikan dari penelitian ini vegan influencer diharapkan dapat lebih konsisten dalam membuat konten, memperbanyak konten mengenai vegan yang sederhana, lebih memahami dan sering menggunakan fitur-fitur Instagram, serta bagi penelitian selanjutnya diharapkan dapat mengembangkan penelitian mengenai vegan influencer dalam aspek influencer marketing.
\end{abstract}

Kata Kunci: fenomenologi, instagram, vegan influencer, makna, pengalaman komunikasi

\section{PERSONAL BRANDING OF INSTAGRAM'S VEGAN INFLUENCER}

\begin{abstract}
Indonesia is the 16th best country to live a vegan lifestyle. Even so, the number of vegans in Indonesia is still small. The purpose of this research is to find out the meaning of vegan for vegan influencers, the motives of vegan influencers in building personal branding on Instagram, and vegan influencer communication experiences in building personal branding on Instgaram. The theory used in this research is Schutz's Phenomenology Theory and Symbolic Interaction Theory by George Herbert Mead. This research uses the phenomenological method and constructivism paradigm. The results of this study from 10 subjects, indicate that vegan influencers define vegan as and for health, environment, ethics, and food. The vegan influencer motives are categorized into 2 categories, firstly because-motive and in-order-to-motives. Vegan influencer communication experiences in building personal branding on Instagram are divided into two, namely the communication experience when you first became a vegan influencer on Instagram and after becoming a vegan influencer on Instagram. The advice that can be given from this research is that vegan influencers are expected to be more consistent in creating content, increase content about simple vegans, better understand and frequently use Instagram features, and for further research it is hoped that it can develop research on vegan influencers in the influencer marketing aspect.
\end{abstract}

Keywords: phenomenology, vegan influencer, Instagram, meaning, communication experience 


\section{PENDAHULUAN}

Penelitian yang dilakukan oleh (Greger, 2016) telah menunjukkan bahwa pola makan dengan mengkonsumsi bahan nabati atau vegan dapat membantu mencegah dan mengobati beberapa penyebab kematian seperti penyakit jantung, diabetes tipe dua, serta tekanan darah tinggi. Studi intervensi dari pola makan nabati telah menunjukkan adanya penurunan sebesar $90 \%$ terhadap serangan angin dalam beberapa minggu. Untuk memaknai vegan sendiri dibagi menjadi 2 pemaknaan yaitu Hard Veganism dan Soft Veganism. Pemaknaan mengenai Hard Veganism berfokus pada pembenaran moral melalui cara-cara vegan. Justifikasi moral ini berhubungan dengan krisis bahan pangan ternak dan tanggungjawab pribadi ssebagai sesama makhluk hidup yang tinggal di bumi, untuk mencegah bencana alam, melindungi binatang, dan menjaga kesahatan lewat konsumsi makanan vegan (Christopher et al., 2018). Hard Veganism sering dihubungkan dengan kepercayaan moral dan tindakan untuk mencegah dan mengatasi masalah alam di lingkungan. Sementara pemaknaan mengenai Soft Veganism membicarakan seputar kesehetan yang didapat dengan menjadi seorang vegan industri makanan yang menyediakan banyak opsi makanan vegan, dengan tujuan agar mempermudah orang-orang untuk mengonsumsi makanan vegan. Makanan vegan juga digunakan untuk membangun kelompok kecil yang bertujuan melawan pandangan stereotip bahwa vegan hanya ditujukan untuk orang-orang kelas menengah atas dan meruntuhkan beberapa penghalang yang mencegah beberapa orang untuk terlibat dengan gaya hidup vegan (Harper, 2012)

Berdasarkan data dari Oliver's Travel (Oliver, 2021) yang diterbitkan dalam The Global Vegetarian Index, Indonesia merupakan salah satu negara terbaik untuk menikmati hidangan vegan. Adapun peringkat ini dilihat dan dinilai dari jumlah konsumsi daging tahunan, jumlah restauran vegan di Indonesia, dan kisaran jumlah vegan di Indonesia. Indonesia menempati peringkat 16 dari 20 negara terbaik dari total 183 negara yang masuk ke dalam penelitian tersebut.Walau masuk ke dalam 20 besar negara yang ramah vegan di dunia, Dr. Susianto Tseng, Ketua dari World Vegan Organisation (WVO) \& Vegan Society of Indonesia (VSI) menyatakan bahwa penduduk Indonesia yang menggeluti gaya hidup vegan pada tahun 2021 jumlahnya hanya 2\% dari jumlah seluruh penduduk Indonesia (2021, 3 Maret). Dr. Susianto juga mengatakan bahwa alasan mengapa kebanyakan masyarakat Indonesia belum menggeluti gaya hidup vegan karena kurangnya edukasi dan pengetahuan mengenai perbandingan nutrisi antara makanan vegan dan non-vegan dan didasari oleh karena adanya stereotip atau pandangan bahwa gaya hidup vegan mahal. Menurut Dr. Ssuainto ada banyak miskonsepsi mengenai gaya hidup vegan lebih mahal dibanding makanan yang umum dimakan masyarakat khususnya Indonesia.

Sementara di UK terdapat sekitar 3,5 juta penduduk yang menggeluti gaya hidup vegan pada tahun 2021. Angka ini naik drastis dibandingkan dengan tahun 2014 dimana hanya terdapat 150.000 orang vegan di UK. Popularitas vegan di UK, dapat disebabkan oleh influencers yang menggunakan platform media sosial Instagram untuk memberikan informasi mengenai vegan dan bagaimana hidup sebagai seorang vegan (Wilson, 2019). Influencer memiliki daya mempengaruhi yang sangat kuat sebagaimana mereka menyediakan dan membagikan informasi seputar vegan dari berbagai prespektif dan cara, baik itu melalui 
sektor kesahatan, lingkungan maupun etiket moral. Instagram dipandang sebagai sebuah alat personal branding untuk mendapatkan perhatian dan popularitas secara online (Chang, 2014). Lewat Instagram, pengguna dapat bebas memilih mana influencer yang kiranya menarik perhatian mereka dan belajar mengenai vegan. Sesama pengguna sebagai pengikut dari seorang influencer juga dapat bertukar pikiran seputar vegan, dengan secara bersamaan dibimbing oleh influencer tersebut yang lebih memiliki pengalaman dan ilmu. Karena itu, influencer Instagram memiliki kuasa yang besar untuk menyebarluaskan dan mempersuasi orang banyak untuk mengikuti dan menerapkan gaya hidup vegan.

Sebagian besar penelitian akademis mengenai vegan berfokus pada media trandisional seperti kampanye hak-hak hewan, televisi, surat kabar, dan dokumenter. Semua fenomena yang dialami atau dilihat oleh individu, disimpan di dalam ruang kesadaran individu dan berwujud sebagai pengalaman bagi individu itu sendiri. Pengalaman dapat berhubungan dengan berbagai dimensi dan sisi kehidupan individu termasuk komunikasi. Tiap individu pasti memiliki pengalaman dalam berkomunikasi dengan individu lain. Pengalaman komunikasi individu bersifat relatif dan subjektif (Hakim et al., 2017). Karena itu, salah satu tujuan dari penelitian ini adalah untuk mengeksplorasi pengalaman komunikasi influencer vegan kontemporer di media sosial Instagram untuk menunjukan gambaran vegan pada 'generasi media sosial'.

Vegan influencer di Instagram sangatlah memiliki kuasa yang besar karena mereka memberikan orang-orang pengetahuan seputar makanan vegan dan posisi pemilihan makanan lewat pandangan yang lebih luas mulai dari wacana sosial tentang risiko, kebencian, tanggung jawab dan moralitas (Jallinoja et al., 2018). Melalui media sosial, personality seseorang akan dinilai berdasarkan apa yang ditulis olehnya. Instagram merupakan salah satu media sosial yang digunakan sebagai wadah untuk membentuk image yang diinginkan, karena pengguna Instagram harus mampu untuk membuat persepsi positif dan sesuai dengan image yang akan dibentuk. Pada manusia, brand yang ada pada diri mereka disebut dengan personal brand. Adanya kemudahan pada era digital ini membuat siapa saja bisa menjadi vegan influencer, sehingga personal brand menjadi sesuatu yang penting untuk dilakukan. Branding yang dilakukan dan diterapkan sebagai tanda utama perseorangan, sehingga disebut sebagai personal branding (Anshari, 2013). Personal branding yang ditampilkan di Instagram tidak hanya menunjukan kepribadian saja, lebih dari itu akan mengilustrasikan dimensi personal branding yang meliputi kompetensi, standar dan gaya (Mudrikah, 2020). Dimensi ini merupakan dimensi utama pembentukan personal branding (McNally, D., \& Speak, 2004). Terdapat banyak sekali konsep yang dapat disajikan dasar landasan berpikir mengenai tinjauan Personal branding. Untuk menyederhanakannya, (McNally, D., \& Speak, 2004) mengerucutkan ide-ide mengenai Personal branding dalam tiga dimensi, yaitu Kompetensi, Standar, dan Gaya. Personal branding tersebut dapat dipengaruhi dari latar belakang tiap individu yang memiliki perbedaan antar satu sama lain. Sehingga dengan personal branding dari tiap influencer dapat membantu menarik perhatian dan meningkatkan awareness masyarakat atas vegan khususnya di Indonesia serta dari pengalaman influencer selama membangun personal branding-nya di Instagram dapat ditelaah pengemasan vegan seperti apakah yang bisa diterima oleh masyarakat Indonesia. 
Berdasarkan fenomena berkembangnya makanan vegan di Indonesia dan munculnya vegan influencer di Instagram, maka fokus kajian dari penelitian in adalah "Bagaimana vegan influencer membangun personal branding di Instagram?" Penelitian ini merupakan studi fenomenologi mengenai personal branding dari 10 vegan influencer di Instagram. Adapun pertanyaan penelitian yang terlahir dari fokus penelitian adalah sebagai berikut: (1) Bagaimana pemaknaan vegan bagi vegan influencer? (2) Bagaimana motif vegan influencer dalam membangun personal branding di Instagram? (3) Bagaimana pengalaman komunikasi vegan influencer dalam membangun personal branding di Instagram?

\section{METODE PENELITIAN}

Penelitian ini menggunakan metode penelitian kualitatif dengan pendekatan fenomenologi Alfred Schutz yang mengkaji fenomana personal branding vegan influencer melalui sudut pandang vegan influencer Instagram. Penelitian mengacu pada asumsi di mana setiap tindakan selalu dilandasi oleh pengalaman, makna dan kesadaran, oleh karena itu objek penelitian ini adalah personal branding dari para vegan influencer. Teknik penentuan narasumber yang dipakai merupakan teknik purposive sampling, yaitu teknik pengumpulan sampel dengan beberapa konsiderasi yang sudah ditentukan (Sugiyono, 2013). Peneliti menentukan konsiderasi atau kriteria kunci untuk narasumber dalam penelitian ini yaitu sebagai berikut: (1) Narasumber menjadikan gaya hidup vegan sebagai konten utama pada akun Instagramnya; (2) Narasumber aktif mengunggah konten di Instagram setiap hari pada Instagram Story maupun Instagram Feeds; (3) Narasumber memiliki lebih dari 1.000 followers di Instagram; (4) Narasumber bersedia melaksanakan wawancara dengan peneliti; (5) Narasumber bersedia untuk diwawancarai dan hasilnya akan dipublikasikan dalam penelitian ini. Berdasarkan kriteria yang telah ditentukan di atas, maka terpilih 3 orang vegan influencer yang dijadikan key informant pada penelitian ini seperti yang tertera pada tabel berikut:

Tabel 1 Daftar Subjek Penelitian

\begin{tabular}{|l|l|l|l|l|}
\hline No & Nama & Username & Followers & Pekerjaan \\
\hline 1. & Sarrah Mita & @sarrahmita & 6 ribu & Ahli Nutrisi \\
\hline 2. & Bunga Mega & @bunga_mega & 10 ribu & Life Coach \\
\hline 3. & Arima & @cleaneatingnoob & $2,8 \mathrm{ribu}$ & Karyawan \\
\hline 4. & Adeline Sasongko & @jakartaplantbased & $3 \mathrm{ribu}$ & Artist \\
\hline 5. & Yani Alvina & @veganindonesian & $4 \mathrm{ribu}$ & Pengusaha \\
\hline 6. & Rhea Laras & @rhealaras & $3,5 \mathrm{ribu}$ & Pengusaha \\
\hline 7. & Intan Shavira & @intanvr & $1,6 \mathrm{ribu}$ & Mahasiswi \\
\hline 8. & Melissa Ginting & @dmaylisa & $8,5 \mathrm{ribu}$ & Pengusaha \\
\hline 9. & Mercy Andrea & @mercyandrea & $4,6 \mathrm{ribu}$ & News Anchor \\
\hline 10. & Yoesi Ariyani & @yoear & 28 ribu & Pengusaha \\
\hline
\end{tabular}

Sumber: Hasil Penelitian, 2021

Dikarenakan pandemi COVID-19 sesuai anjuran pemerintah untuk melakukan aktivitas dari rumah, peneliti akan melakukan penelitian dari rumah peneliti dan mengumpulkan informasi dari subjek penelitian lewat media daring. Sedangkan untuk waktu penelitian akan dimulai sejak waktu diterbitkannya izin untuk melakukan penelitian yaitu bulan Desember 2020 sampai selesai. 
Data diperoleh melalui wawancara mendalam, observasi non-partisipatif, studi pustaka, dan penelusuran online, yang kemudian dianalis sejumlah tahapan berikutnya, antara lain: 1) Reduksi Data. Mereduksi data artinya meringkas, menseleksi data yang utama, memprioritaskan untuk hal penting, dianalisis tema, serta polanya. Dengan demikian, data yang sudah di reduksi akan menyajikan ilustrasi yang lebih lugas, dan membantu peneliti dalam menjalankan pengumpulan data selanjutnya, dan mencarinya jika diperlukan. (Sugiyono, 2015:92), 2) Penyajian Data, sesudah data di reduksi, maka langkah selanjutnya yaitu menampilkan data dengan penyajian data. Melalui penyajian data tersebut, maka data dapat diorganisir dan disusun menggunakan pola relasi, sehingga akan lebih mudah diidentifikasi., 3) Penarikan Kesimpulan dan Verifikasi. Tahap ketiga adalah analisis data kualitatif, yang disebut oleh Miles dan Huberman sebagai pengambilan verifikasi dan kesimpulan. Kesimpulan awal yang disajikan masih berupa kesimpulan tempores dan bisa berubah jika tidak menemukan bukti kuat yang mendukung dalam tahap pengumpulan data selanjutnya (Sugiyono, 2013).

\section{HASIL DAN PEMBAHASAN}

\section{Pemaknaan Vegan bagi Vegan Influencer}

Menurut Schutz, peran fenomenologi adalah menghubungkan antara pengalaman seharihari dan pengetahuan ilmiah dari kegiatan dimana pengetahuan dan pengalaman itu berasal, atau memiliki arti mendasarkan tindakan sosial pada pengalaman, makna, dan kesadaran (Kuswarno, 2009). Selama proses wawancara mendalam, peneliti mengajukan beberapa pertanyaan untuk mencari tahu pengalaman para vegan sebagai vegan influencer. Sebelum mengetahu lebih dalam mengenai pengalaman para vegan influencer, peneliti memulai pertanyaan dari awal mula vegan influencer memilih gaya hidup vegan dan memaknai vegan itu sendiri hingga ia dapat membentuk personal branding nya sendiri sebagai seorang vegan influencer yang tercermin di Instagram. Dari pertanyaan-pertanyaan tersebut diperoleh hasil yang cukup beragam.

\section{Makna Vegan Untuk Kesehatan}

Beberapa vegan influencer memaknai vegan sebagai suatu usaha untuk mencegah dan menanggulangi penyakit serta menjaga kesehatannya baik fisik maupun mental. Berdasarkan hasil penelitian, informan telah mengetahui adanya bibit penyakit pada genetiknya yang disebabkan oleh penyakit keturunan. Informan kemudian mencegah penyakit dengan mengikuti gaya hidup vegan dengan harapan agar ia dapat terhindar dari suatu penyakit. Selain pencegahan, informan juga melakukan penanggulangan penyakit yang telah diderita seperti penanganan alergi dan mengurangi bobot berat badan. Salah satu cara untuk mengobat suatu penyakit adalah dengan tidak mengonsumsi daging hewani dan lebih lanjut mengubah pola hidup menjadi vegan.

Selain itu, bagi informan yang tidak memiliki masalah kesehatan, memaknai vegan sebagai jalannya untuk menjaga kesehatannya. Dengan beralih ke pola hidup vegan, informan mendapatkan gizi dan nutrisi yang mereka butuhkan dari makanan nabati dan tidak mendapatkan zat-zat berbahaya bagi tubuh yang terdapat pada daging hewan. Selain itu informan juga memiliki stamina yang lebih besar dibandingkan saat mereka belum mengikuti 
gaya hidup vegan dan dibandingkan dengan orang sekitar mereka yang tidak vegan.Dr. Susianto Tseng menyatakan bahwa dari banyak jurnal penelitian sudah dibuktikan bahwa ada keterkaitan antara pola makan vegan dengan zat gizi yang dibutuhkan tubuh untuk mencegah penyakit degeneratif seperti kanker, jantung, hipertensi, diabetes, dll (2021, 30 Maret).

Selain menghindari dan berupaya untuk sembuh dari penyakit, informan juga menjadi vegan untuk menunjang kesehatan mentalnya. Beberapa manfaat yang dialami langsung oleh informan kepada kesehatan mentalnya adalah tidak mudah emosi, tidak mudah lelah, dan tidak mudah berpikiran negatif. Vegan dalam sudut pandang kesehatan dikemas dalam informasi yang mengedukasi dan mudah diingat dengan menggunakan retorika emosional, bukti sains dan kesaksian dari individu. Mereka menemukan bahwa wacana tentang vegan kesehatan memperkuat ideologi tentang kesehatan, individualisme, dan tanggaung jawab sebagai diskusi yang berpusat pada 'cara makan dengan benar' untuk mendapatkan kesehatan optimal (Christopher, A., Bartkowski, J., \& Haverda, 2018).

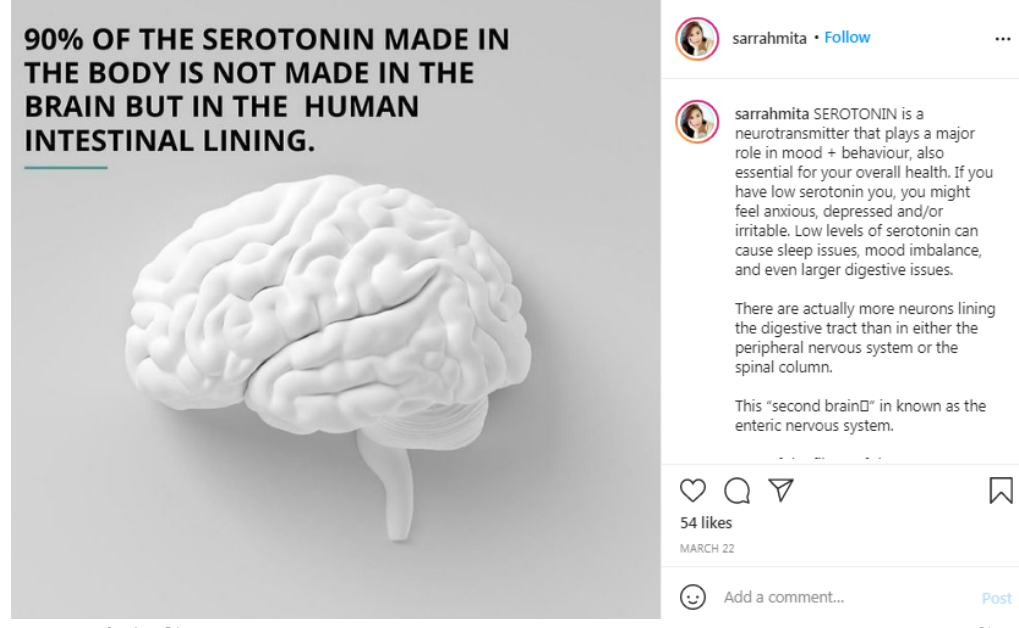

Gambar 4.1 Contoh Pemaknaan Vegan Untuk Kesehatan oleh Sarrah

\section{Makna Vegan Untuk Lingkungan}

Selain kesehatan diri, informan juga memaknai vegan sebagai alat untuk menjaga kesehatan lingkungan. Ada beragam cara untuk menjaga kesehatan lingkungan mulai dari daur ulang, mengurangi pemakaian kendaraan, membatasi pemakaian peralatan elektronik, hingga mengurangi konsumsi hewani dan turunannya dari menu makanan sehari-hari atau menjadi vegan. Untuk menekan gas metana di bumi, informan kemudian beralih menjadi vegan karena mereka rasa kepedulian mereka yang tinggi kepada bumi. Mereka berharap, lewat vegan mereka dapat memberikan kontribusinya bagi bumi. Lebih lanjut, informan tidak bermaksud untuk mematikan usaha dari para peternak, tetapi dengan seiring berjalannya waktu memberikan informasi dan pengertian akan bahaya dari peternakan bagi lingkungan dan bahaya tersebut dapat ditekan secara perlahan dengan menjadi vegan sampai ditemukannya cara lain untuk menekan gas metana yang ada di atmosfer. Karena kepedulian pada lingkungan, informanpun memaknai vegan sebagai salah satu cara mereka untuk menyelamatkan bumi dan memberi kontribusi pada lingkungan. 
Dari hasil penelitian terhadap vegan di UK mereka menyebutkan dan membagi posisi manusia menjadi dua. Pertama adalah 'pemakan daging' yang dikonstruksi sebagai kelompok manusia yang menyebabkan perubahan iklim di bumi, karena atas daging yang mereka konsumsi memberikan kontribusi untuk merusak bumi, mengingat bahwa peternakkan hewan merupakan kontributor terbesar bagi gas rumah kaca. Sebaliknya, golongan kedua adalah kelompok manusia vegan yang dikonstruksi sebagai orang yang rendah hati, bermoral, dan bertanggungjawab atas tindakannya untuk melindungi bumi (Wilson, 2019). Informan yang memaknai vegan untuk lingkungan, merasa dengan beralih ke gaya hidup vegan merupakan hal termudah dan paling bermanfaat yang bisa dilakukan untuk bumi, karena manusia memiliki kuasa untuk memilih makanan untuk dikonsumsi.

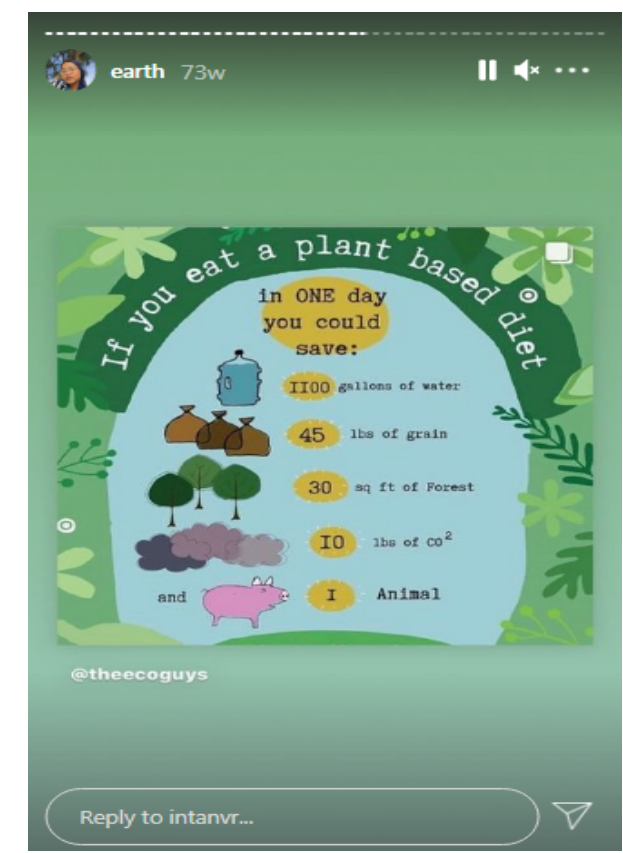

Gambar 4.2 Contoh Pemaknaan Vegan Untuk Lingkungan oleh Intan

\section{Makna Vegan Sebagai Etika}

Beberapa vegan influencer memaknai vegan sebagai etika terhadap sesama makhluk hidup. Mereka memiliki keyakinan dan nilai tersendiri terhadap perlakukan terhadap sesama makhluk hidup. Mereka tidak memaknai vegan untuk diri sendiri atau untuk lingkungan, melainkan karena rasa iba terhadap makhluk hidup yang harus dibunuh untuk kepentingan konsumsi dan hidup manusia.

Lebih lanjut mengenai pemaknaan etika, vegan influencer tidak setuju dengan eksploitasi hewan untuk konsumsi manusia karena menurut mereka, hewan sama seperti manusia merupakan makhluk hidup yang layaknya manusia, memiliki rasa menyanyangi dan rasa sakit. Vegan dilihat dari sudut pandang etika bukan hanya mengenai pola makan tetapi gaya hidup moral dan politik komitmen yang meluas ke pakaian dan produk lainnya. Akibatnya, konstruksi vegan ini berpendapat bahwa untuk menjadi vegan anda harus terlibat dalam gaya hidup yang menantang cara berpikir 'normal' seperti mengonsumsi hewan (Jallinoja et al., 2018). 
Di Indonesia sendiri pemaknaan vegan lewat pendekatan etika masih lebih sulit diterima dibandingkan lewat pendekatan kesehatan dan lingkungan. Hal ini dikarenakan adanya suku dan kelompok di Indonesia yang memiliki budaya untuk mengonsumsi hewan. Sehingga beberapa influencer sempat mendapat kritikan dan dianggap sebagai ekstrimis yang tidak menghargai budaya dan pemberian Tuhan. Kata ekstrimis sendiri menurut KBBI adalah 'orang yang melampaui batas kebiasaan (hukum dan sebagainya) dalam membela atau menuntut sesuatu.' Karena itu, walau mereka telah memiliki kepercayaan sendiri terhadap etika kepada sesama makhluk hidup, mereka belum berani untuk menyuarakan secara vokal mengenai kepercayaan mereka seputar etika terhadap makhluk hidup karena masih menghormati kebudayaan yang ada. Menurut mereka juga, kebudayaan bukanlah sesuatu yang mudah untuk dirubah karena telah terbentuk dalam waktu yang lama dan sudah dilaksanakan secara turun temurun.

Peneliti juga menemukan, unggahan seputar pemaknaan vegan mengenai etika mayoritas memiliki caption dengan Bahasa Inggris. Pengguna Instagram menggunakan caption dengan Bahasa Inggris untuk menceritakan atau menjelaskan foto yang diunggah di akun Instagramnya. (Ardianti, 2018). Penggunaannya sesuai dengan kebutuhan yang berbeda-beda sesuai dengan perilaku pengguna baik terencana maupun tindakan spontan tanpa terencana. Dalam pemaknaan mengenai etika, pemilihan caption dengan Bahasa Inggris digunakan karena materi mengenai etika terhadap makhluk hidup lebih populer di negara yang menggunakan Bahasa Inggris dibandingkan di Indonesia. Karena itu, informan merasa lebih cocok dan nyaman untuk menyuarakan pemaknaannya seputar etika terhadap makhluk hidup dengan bahasa awal materi tersebut dibaut yaitu dengan Bahasa Inggris.

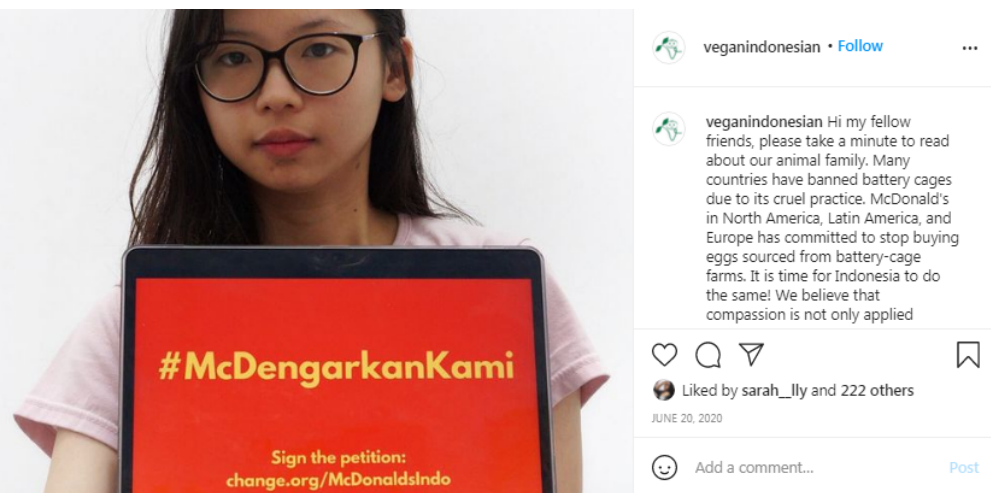

Gambar 4.3 Contoh Pemaknaan Vegan Sebagai Etika oleh Yani

Penggunaan internet dan teknologi informasi itu tergantung pada budaya demokrasi. Kalau budaya demokrasi kita tidak dewasa, maka itu (penggunaan internet secara dewasa) juga tidak akan terbentuk, Untuk kasus di Indonesia misalnya, budaya demokrasi di Indonesia belumlah menunjukkan kedewasaannya. Hal ini bisa dilihatnya dari praktik kebebasan berpendapat yang tidak diikuti dengan rasa saling menghargai terhadap perbedaan pendapat. Bahkan perbedaan pendapat seringkali menjadi bahan olok-olok atau bullying. Banyak meme yang berseliweran di media sosial sebagai bentuk olok-olok, bahkan sosok presiden pun menjadi bahan olok-olok politik di media. Selain itu, dalam konteks Pemilihan Presiden (Pilpres) 2019 yang lalu misalnya, perbedaan pilihan dapat memicu adu fisik hingga menimbulkan jatuhnya korban. Indikator lainnya adalah informasi yang beredar tidak 
substantif dan tidak ada keragaman informasi. Karena tanpa keragaman, maka demokrasi akan hilang. Dapat dikatakan, media sosial belum dapat mendukung demokrasi digital. Di sini budaya demokrasi perlu dibenahi. Sebab, yang menjadi fokus dalam demokrasi digital adalah kontennya, bukan perangkat keras yang digunakan, seperti halnya media sosial.

\section{Makna Vegan Sebagai Makanan}

Terdapat stereotip bahwa makanan vegan mahal dan cenderung memiliki menu yang identik dengan maknaan barat seperti salad yang hanya berisi sayur hijau. Pandangan ini tercipta karena gaya hidup vegan tidak dilahirkan di Indonesia dan datang dari luar Indonesia. Tokoh-tokoh vegan dari luar Indonesia juga memiliki personal branding sebagai seorang dengan gaya hidup menengah keatas, memberi pandangan bahwa gaya hidup vegan mahal dan hanya untuk kalangan tertentu.

Para influencer vegan sepenuhnya menolak kebenaran akan stereotip ini. Menurut mereka, mahal atau murahnya makanan tergantung makanan seperti apa yang dibeli oleh individu. Influencer vegan banyak memberi contoh makanan warteg atau warung tegal yang menjual variasi menu makanan Indonesia dengan harga yang murah. Mereka memberi pengertian bahwa kebanyakan makanan yang ada pada warteg terbuat dari nabati sehingga aman dikonsumsi oleh vegan. Jika dibandingkan dengan dagingpun, sayur, jamur, dan kacang-kacangan memiliki harga yang lebih murah di pasaran. Dengan ini, para vegan influencer membantah pernyataan gaya hidup vegan yang mahal. Hal ini sejalan penelitian pada Greenebaum, (2018) ia mengumpulkan sejumlah orang yang memiliki gaya hidup vegan dan mengolah makanan khas budaya mereka dari bahan-bahan vegan seperti buah-buahan, sayura, biji-bijian, dan kacang-kacangan. Lebih lanjut, orang-orang vegan yang bukan dari kalangan menengah keatas menyatakan dengan gaya hidup vegan, makanan mereka seharihari menjadi lebih murah karena mereka mengolah sendiri makanan mereka dan tidak membeli makanan olahan dari luar.
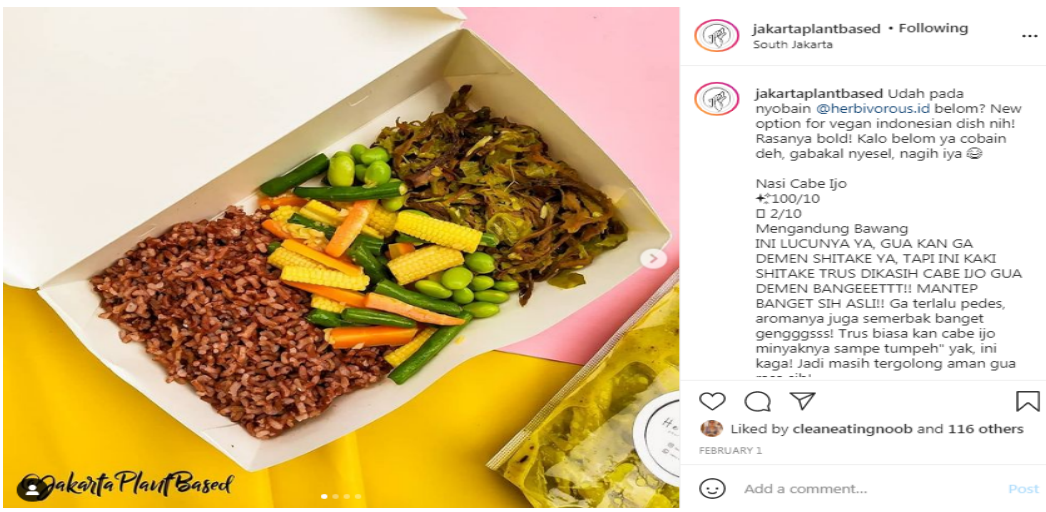

Gambar 1.4 Contoh Pemaknaan Vegan Sebagai Makanan oleh Adeline

\section{Motif Vegan Influencer dalam Membangun Personal Branding di Instagram}

Teori yang dijadikan acuan pada penelitian ini adalah Teori Fenomenologi dari Alfred Schutz. Mengikuti pemikiran Schutz tentang motif, ia membagi motif dengan memberi identitas dua fase, yaitu Schutz mengusulkan dua fase, yaitu In-order-to-motive, yaitu tujuan yang digambarkan sebagai maksud, rencana harapan, dll, yang berorientasi masa depan dan 
yang kedua, Because-motive yang merujuk pada pengalaman masa lalu individu (aktor) karena berorientasi masa lalu (Kuswarno, 2009).

\section{Because Motives}

Beberapa motif vegan influencer dalam membangun personal branding di Instagram yang ditemukan oleh peneliti yaitu jumlah vegan influencer Indonesia di Instagram yang masih sedikit, terinspirasi oleh vegan influencer dari luar Indonesia dan kesenangan medokumentasikan gaya hidup vegan dalam kehidupan sehari-hari. Ketiga motif ini termasuk kedalam because motives karena merujuk pada masa lalu informan sebelum mereka memutuskan dan terdorong untuk menjadi seorang vegan influencer.

Motif pertama pada because motives adalah belum banyaknya vegan influencer di Instagram. Salah satu cara efektif untuk mempromosikan suatu usaha adalah melalui promosi yang dilakukan influencer di Instagram (Wilson, 2019). Dengan mempertimbangkan kebutuhan mendesak untuk pengurangan global dalam konsumsi daging dan kekuatan suara orang berpengaruh mengenai gaya hidup vegan, vegan 'Influencer' adalah tokoh yang sangat penting untuk penyebaran informasi karena mereka menyediakannya pengetahuan tentang bagaimana menjalani hidup tanpa daging (EATLancet, 2019). Karena masih sedikitnya vegan influencer ditengah industri dan pasar vegan yang semakin terus berkembang, para informan merasa adanya peluang bagi mereka untuk masuk ke dunia vegan influencer. Masih sedikitnya vegan influencer di Instagram menjadikan motif para vegan influencer untuk beralih dan membangun personal brandingnya sebagai vegan influencer di Instagram. Mereka melihat adanya peluang dan celah untuk mempromosikan gaya hidup vegan kepada orang awam beriringan dengan terus berkembangnya industri dan pasar vegan di Indonesia. Dengan keadaan seperti itu, menjadi mereka opsi pertama bagi para pelaku usaha vegan untuk melakukan taktik dagang mempromosikan produknya di Indonesia lewat vegan influencer.

Motif kedua adalah terinspirasi oleh vegan influencer dari luar Indonesia Fenomena vegan influencer pertama dan terbesar diawali di United Kingdom atau UK. Salah satu organisasi vegan terbesar di dunia, yaitu Vegan Society dibangun pertama kali di UK pada tahun 1944. Sebagai negara pelopor, hal ini juga menjadi faktor pesatnya pertumbuhan jumlah vegan influencer yang menyuarakan vegan lewat akun Instagram mereka. Sejak saat itulah menjadi awal mula munculnya vegan influencer di luar negri. Melirik kesuksesannya vegan influencer di luar negri terutama di UK, menginspirasi dan menjadi motif para vegan influencer Indonesia membangun personal brandingnya di Instagram. Dengan melihat konten yang diunggah oleh influencer, individu merasakan efek positif secara psikologis. Setelah melihat konten influencer yang bertujuan untuk mempengaruhi seseorang, individu dapat merasa lebih percaya diri, lebih mudah bersosialisasi, lebih terinspirasi untuk mencoba hal-hal baru (Mahdia, 2018).

Motif ketiga adalah senang mendokumentasikan gaya hidup vegan. Sebagai seorang influencer, hal termudah untuk didokumentasikan dan diunggah ke media sosial Instagram adalah kehidupannya sehari-hari. Setiap harinya, individu pasti akan mengonsumsi makanan untuk mendapatkan nutrisi dan energi yang dibutuhkan. Sama seperti vegan influencer yang setiap hari mengonsumsi makanan vegan. Membagikan informasi 
kehidupan sehari-hari merupakan bagian dari proses komunikasi antarmanusia. Media sosial telah menciptakan suatu kebutuhan untuk saling terkoneksi antar satu sama lain. (Maudia et al., 2018). Karena itu, salah satu konten yang paling mudah untuk diunggah dan dibuat adalah dokumentasi gaya hidup vegan dalam kehidupannya sehari-hari seperti dokumentasi makanan yang disantap oleh para vegan influencer. Keterampilan yang dimiliki informan dalam mendokumentasikan gaya hidup vegannya menunjang kompetensi yang menurut McNally dan Speak (2004:43) diperlukan untuk memenuhi suatu kebutuhan atau memuaskan keinginan followers pada akun Instagram para informan sebagai vegan influencer.

Fase kedua berdasarkan pembagian Schutz adalah In order to motives atau motif untuk berkaitan dengan alasan seseorang melakukan suatu tindakan sebagai usahanya menciptakan situasi dan kondisi yang diharapkan di masa datang. Dengan kata lain motif ini merupakan gambaran tujuan para informan atau maksud, harapan, rencana, minat dan sebagainya yang berorientasi pada masa depan. In order to motives merujuk pada sebuah keadaan pada masa yang akan datang informan berkeinginan untuk mencapai tindakannya melalui beberapa tindakannya. Untuk itu sering kali motif ini disebut motif untuk atau motif tujuan.

Dalam penelitian ini, terdapat lima in order to motives yang menjadi motif para vegan influencer membangun personal branding di Instagram. Motif-motif tersebut antara lain adalah memberi informasi seputar vegan, mempengaruhi orang untuk beralih menjadi vegan, menjaga kesehatan diri, mendapat penghasilan, dan eksistensi sebagai vegan influencer.

Motif pertama pada in-order-to-motive adalah memberi informasi seputar vegan. Untuk memberikan informasi, seorang vegan influencer harus memiliki wawasan luas dan kompetensi untuk menyuarakan mengenai vegan agar informasi yang disebarkan adalah benar. Menurut Notoatmodjo (2003), Pengetahuan (knowledge) merupakan hasil dari "tahu", dan ini terjadi setelah orang melakukan penginderaan terhadap suatu objek tertentu yang terjadi melalui panca indera manusia yakni indera penglihatan, pendengaran, penciuman, rasa, dan raba yang sebagian besar pengetahuan manusia diperoleh melalui mata dan telinga. Sementara mengenai kompetensi, Spencer dan Spencer dalam Hamzah B. Uno (2007: 63) memberikan pendapatnya mengenai kompetensi yang merupakan karakteristik yang menonjol bagi seseorang dan menjadi cara-cara berperilaku dan berfikir dalam segala situasi, dan berlangsung dalam periode waktu yang lama. Kapabilitas sering diartikan sebagai kemampuan dan keterampilan (skill) secara lengkap dalam menguasai dan mengatasi persoalan (Rusmulyadi \& Hafiar, 2018). Menurut Zata Liguow seorang ahli digital personal branding yang menjadi triangulator dalam penelitian ini, Instagram merupakan platform media sosial yang tepat untuk membangun personal branding karena mudah untuk digunakan dan memungkinkan adanya pertukaran informasi yang memperluas jangkauan vegan influencer dalam menyebarkan informasi seputar vegan (2021, 14 April).

Motif kedua adalah mempengaruhi orang untuk beralih menjadi vegan, karena semakin banyak orang yang beralih menjadi vegan, maka semakin banyak pula orang yang 
merasakan kebermanfaatan vegan pada tubuhnya, membantu menyelamatkan lingkungan, mengurangi penyiksaan terhadap hewan, dan membantu bisnis industri vegan. Untuk tujuan tersebut, para vegan influencer menggunakan platform Instagram mereka untuk mempengaruhi orang untuk beralih menjadi vegan. Instagram memungkinkan penyebaran informasi seputar gaya hidup vegan menjangkau masyarakat luas dan memiliki potensi untuk mempersuasi banyak orang mengurangi konsumsi daging hewan. Karena lewat Instagram dapat disediakan informasi vegan secara virtual, maka orang-orang yang biasanya tidak terjangkau oleh kampanye fisik seperti orang-orang yang tinggal di daerah pedesaan dan jauh dari kota, Instagram memungkinkan penyebaran informasi seputar gaya hidup vegan sampai ke mereka (Veron, 2016). Hal ini sesuai dengan pernyataan bahwa kemampuan untuk mendapatkan informasi seputar vegan dari vegan influencers dapat mempengaruhi individu untuk memperluas opsi pemilihan makanan dan mempraktikan gaya hidup yang lebih sehat (Johnston \& Goodman, 2015).

Motif ketiga adalah menjaga kesehatan diri, dimana para vegan influencer menghabiskan waktu untuk membuat konten dan memberi informasi seputar vegan untuk di unggah di Instagram, bukan hanya untuk kepentingan orang lain tetapi juga untuk diri sendiri. Dengan membuat konten, vegan influencer pasti akan menjalani proses mulai dari mencari informasi, uji coba makanan vegan mana yang cocok untuk lidah mereka, dan bertukar informasi mengenai vegan. Dari proses tersebut, vegan influencer dapat memperdalam informasi tambahan seputar vegan untuk diterapkan pada kehidupannya sendiri. Agar bisa menampilkan personal branding, seseorang harus mengenal diri sendiri terlebih dahulu. Kemudian, individu tersebut harus mengetahui bagaimana masyarakat menggambarkan dirinya. William Arruda mengatakan bahwa penting untuk mengetahui siapa diri seseorang untuk membuat dirinya berkembang (Arruda \& Dixson, 2007). Arruda menjelaskan mengenai pentingnya mengetahui diri sendiri untuk personal branding, karena untuk membangun reputasi yang kokoh, seseorang harus memahami dan mengartikulasi apa yang dapat menjadi daya tarik dirinya bagi orang lain. Dibutuhkan suatu usaha yang keras dalam menentukan siapa diri seseorang. Bahkan bagi orang-orang yang memilki kesadaran diri dan introspektif, dalam menemukan siapa dirinya dibutuhkan upaya yang signifikan (Arruda \& Dixson, 2007)

Motif keempat adalah mendapat penghasilan atau pendapatan. Pendapatan dalam kamus manajemen adalah uang yang diterima oleh perorangan, perusahaan, dan organisasi lain dalam bentuk upah, gaji, sewa, bunga, komisi, ongkos dan laba (Mulyani, 2016). Berdasarkan hasil penelitian, peneliti mengklasifikasikan endorsement, undangan mengisi acara, serta kerjasama yang dilakukan antara informan dengan brand maupun komunitas vegan sebagai sarana untuk menghasilkan pendapatan. Dalam kerja sama tersebut, biasanya influencer mempunyai rate card yang merupakan panduan dalam melakukan kerja sama, sementara pihak brand memiliki Memorandum of Understanding (MoU) atau nota kesepahaman bagi dua belah pihak. Dalam rate card tersebut, dijelaskan tentang syarat dan ketentuan yang diberikan influencer dalam melakukan kerja sama (Mariezka et al., 2018). Hal ini dikarenakan para informan menerima keuntungan materi dari ketiga hal tersebut setelah jasanya sebagai seorang vegan influencer di Instagram digunakan. 
Motif terakhir pada in-order-to-motive adalah eksistensi sebagai vegan influencer. Manusia memiliki empat kebutuhan yakni kebutuhan fisiologis, kebutuhan rasa aman, kebutuhan harga diri, kebutuhan sosial, kebutuhan akan penghargaan, dan kebutuhan akan aktualisasi diri (Maslow, 2013). Memperoleh eksistensi merupakan pemenuhan kebutuhan penghargaan secara eksternal, yakni menyangkut penghargaan dari orang lain, prestise, pengakuan, penerimaan, ketenaran, martabat, perhatian, kedudukan, apresiasi atau nama baik. Informan mengaku dengan menjadi vegan influencer membuat dirinya dikenal banyak orang dan dikenal oleh sesama vegan influencer baik yang memiliki jumlah followers lebih banyak ataupun lebih sedikit darinya. Vegan influencer dapat saling berkolaborasi membuat konten seputar vegan dan memperluas jaringan atau mengikuti event-event tertentu yang berkaitan dengan vegan. Dalam hal ini seorang vegan influencer memenuhi kebutuhannya untuk memperoleh penghargaan dengan eksistensi yang diciptakannya dengan menjadi vegan influencer.

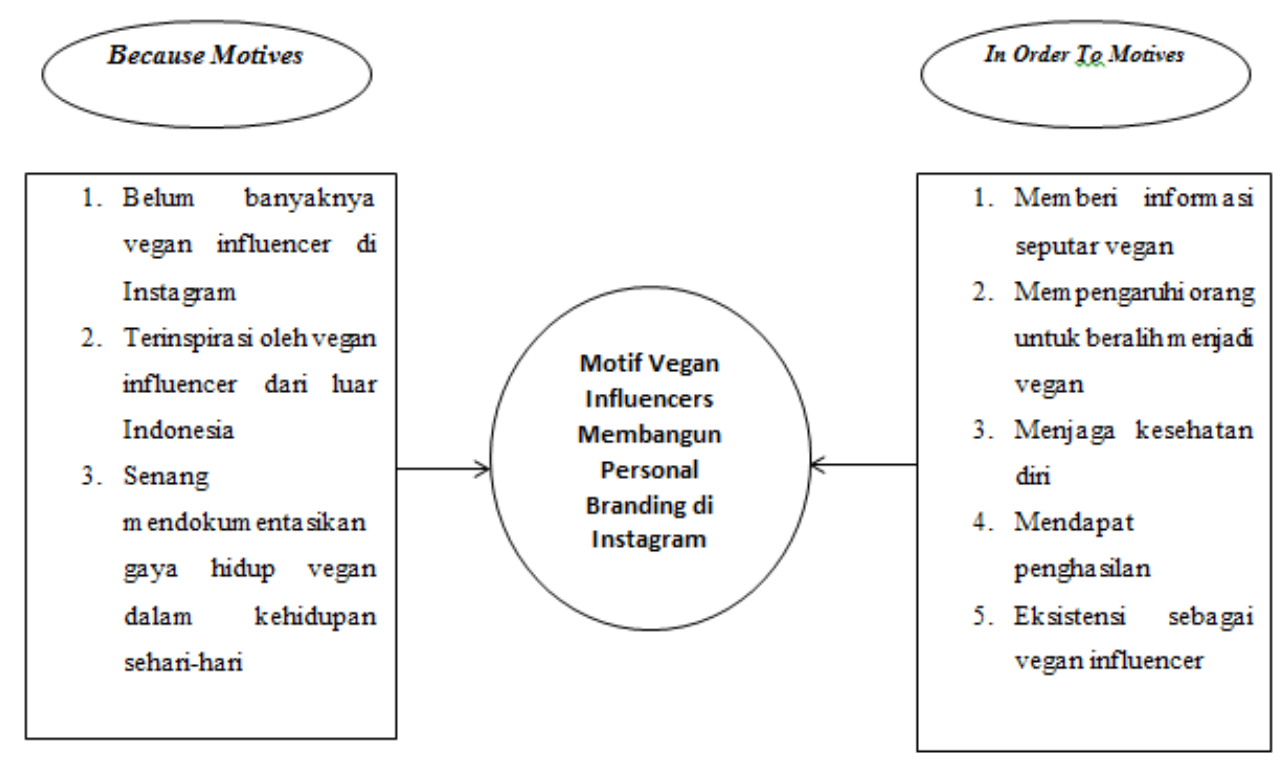

Model 1.1 Motif Vegan Influencer Membangun Personal branding di Instagram

\section{Pengalaman Komunikasi Vegan Influencer dalam Membangun \\ Personal branding di Instagram}

Fenomenologi berfokus pada pengalaman sadar seorang individu. Pandangan fenomenologi tentang manusia adalah bahwa mereka mampu menginterpretasikan pengalaman mereka di lingkungannya secara langsung sehingga mendapatkan suatu pemaknaan dan pemahaman sendiri. Hal ini ditekankan pada interpretasi dan persepsi dari pengalaman subjektif manusia. Karena itu, pengalaman individu adalah hal yang penting dan menentukan konstruksi pemaknaan atas suatu realitas.

Mead dalam (Kuswarno, 2009) menjelaskaan bahwa manusia memiliki kemampuan untuk dapat merespon simbol-simbol ketika berinteraksi yang kemudian memberi penjelasan interaksionalisme simbolik kepada konsep tentang diri. Dalam konteks komunikasi intrapersonal, interaksi simbolik menjelaskan bahwa pikiran terdiri dari percakapan internal yang merefleksikan interaksi yang telah terjadi antara seseorang dengan orang lain. Schutz 
meletakkan hakikat manusia dalam pengalaman subjektif, terutama ketika mengambil tindakan dan mengambil sikap terhadap dunia sehari-hari. Dalam hal ini Schutz mengikuti pemikiran Husserl, yaitu proses pemahaman aktual kegiatan kita, dan pemberian makna terhadapnya, sehingga terefleksi dalam tingkah laku (Kuswarno, 2009).

Pengalaman komunikasi vegan influencer ini merupakan kegiatannya dalam melakukan personal branding di Instagram. Hal ini sejalan dengan teori interaksi simbolik George Herbert Mead yang berasumsi bahwa manusia dapat memahami berbagai hal dengan belajar dari pengalaman. Persepsi seseorang dapat diterjemahkan dalam simbol-simbol. Sebuah makna dipelajari melalui interaksi di antara orang-orang, dan makna tersebut muncul karena adanya pertukaran simbol-simbol dalam kelompok sosial.

Tiga konsep yang dikemukakan Mead pada interaksi simbolik adalah mind, self, dan society. Pikiran adalah kemampuan untuk menggunakan simbol yang mempunya makna sosial yang sama, dimana manusia harus mengembangkan pikiran melalui interaksi dengan orang lain. 3 tema konsep pemikiran George Herbert Mead yang mendasari interaksi simbolik antara lain: (1) pentingnya makna bagi perilaku manusia; (2) pentingnya konsep mengenai diri; dan (3) hubungan antara individu dengan masyarakat. Pemikiran interaksi simbolik menjadi fondasi untuk menjelaskan bagaimana makna atau simbol-simbol yang dipahami oleh vegan influencer membentuk tindakan mereka dalam membangun personal brandingya di Instagram. Makna atas simbol-simbol yang dipahami akan semakin jelas karena adanya interaksi di antara sesama vegan influencer, dengan audiens di Instagram, atau brand dan komunitas vegan sebagai pihak yang menawarkan kerjasama. Pandangan interaksi simbolik membantu menjelaskan bagaimana vegan influencer memandang dirinya sendiri, bagaimana vegan influencer melakukan personal branding berdasarkan pandangan atas dirinya, baik pandangan diri sendiri maupun orang lain terhadapnya.

Pembahasan ini akan dijelaskan oleh peneliti dengan penguraian berdasarkan hasil wawancara dengan informan. Peneliti membagi pengalaman komunikasi vegan influencer dalam membangun personal branding di Instagram dalam dua periodisasi, yaitu pengalaman komunikasi saat awal menjadi vegan influencer di Instagram, dan pengalaman komunikasi setelah menjadi vegan influencer di Instagram. Peneliti kemudian membagi periodisasi pengalaman komunikasi saat awal menjadi vegan influencer di Instagram dilihat dari dua pengalaman, yaitu menjadi vegan sebelum menjadi vegan influencer di Instagram, dan menjadi vegan setelah menjadi influencer di Instagram.

\section{Pengalaman komunikasi saat awal menjadi vegan influencer di Instagram}

Pada bagian ini peneliti akan membahas mengenai pengalaman komunikasi yang dilakukan saat awal membangun personal branding sebagai vegan influencer di Instagram. Informan memiliki pengalaman berbeda yang membuat mereka tertarik untuk menjadi vegan influencer. Peneliti membagi pengalaman komunikasi saat awal menjadi vegan influencer di Instagram menjadi dua, yaitu menjadi vegan sebelum menjadi vegan influencer di Instagram, dan menjadi vegan setelah menjadi vegan influencer di Instagram.

Pada periode ini, informan memaknai diri sebagai individu yang mulai tertarik menjadi seorang vegan influencer di Instagram. Sebagai upaya untuk mengkomunikasikan 
hal tersebut, informan mulai fokus dan konsisten mengunggah konten seputar vegan pada akun Instagramnya. Melalui hal tersebut, audiens di Instagram mengetahui bahwa konten yang akan disajikan oleh para informan adalah terkait vegan, sehingga audiensnya pun akan lebih terbentuk dan proses komunikasi dapat terjadi secara efektif. Informan yang terlebih dahulu menjadi vegan sebelum menjadi vegan influencer sudah mengikuti gaya hidup vegan tanpa mempublikasikan gaya hidupnya di Instagram. Sejak pertama kali mengunggah konten seputar vegan, informan menggunakan gayanya sendiri. Gaya yang dimaksud disini adalah penggunaan caption, pemilihan filter, cara pengambilan foto/video, dan penataan feeds di Instagram. Menurut Zata Liguow, seroang ahli digital personal branding sejak pertama kali individu mengunggah konten di Instagram, dari saat itu pula individu tersebut telah membangun personal brandingnya. (2021, 14 April).

Sementara informan yang terlebih dahulu menjadi seorang influencer sebelum beralih menjadi vegan, telah memiliki standar dan gaya sendiri dalam membangun personal brandingnya di Instagram yang tidak berkaitan dengan vegan. Standar mempengaruhi bagaimana cara orang lain memandang seseorang. Jauh di luar kompetensi yang terlihat pada sebuah hubungan, standar akan mulai memberikan makna terhadap kekuatan personal branding seseorang. McNally dan Speak menjelaskan bahwa meskipun kompetemsi seseorang boleh jadi sama dengan kompetensi dari banyak orang lain, standar seseorang akan membantunya untuk menjadi orang yang terkemuka (McNally, D., \& Speak, 2004).

Karena sebelumnya telah menjadi influencer, baik itu influencer pada bidang kecantikan, olahraga, kesehatan, dan lainnya, influencer memiliki followers yang bercampur yaitu followers yang telah mengikuti mereka sejak sebelum influencer beralih menjadi vegan dan followers yang mengikuti mereka setelah influencer beralih menjadi vegan. Perbedaan audiens ini, menimbulkan beberapa komentar dari 'kubu lawan' ketika influencer menampilkan suatu konten. Jika influencer mengunggah konten seputar vegan, akan ada komentar positif dari followers vegan dan pertanyaan bahkan respon negatif yang datang dari followers non-vegan. Karena itu, influencer harus mengambil resiko untuk memilih ingin melanjutkan membangun personal branding sebagai vegan influencer atau tetap menjadi influencer biasa sebelum ia menjadi vegan. Sebisa mungkin, informan menjawab pertanyaan dan komentar yang masuk sesuai dengan ilmu yang mereka miliki agar tidak menimbulkan mis-konsepsi seputar vegan. Karena itu, influencer melakukan research mendalam mengenai konten vegan seperti apa yang disukai oleh publik. Informan mencari informasi dari buku, browsing internet, melihat contoh dari vegan influencer yang sudah ada, menonton webinar, dan melakukan trial and error sendiri untuk melihat respon seperti apa yang disukai oleh publiknya. Jika mendapat respon positif, influencer akan mengulang konten tersebut, jika mendapat respon negatif atau tidak diberi respon, influencer akan mengurangi jenis konten tersebut.

\section{Pengalaman komunikasi setelah menjadi vegan influencer di Instagram}

Pada bagian ini, Instagram tetap dijadikan sebagai platform utama yang aktif digunakan setiap harinya oleh para informan, baik pada Instagram stories ataupun feeds. Audiens pada bagian ini pun sudah terbentuk, yaitu pengguna Instagram yang memiliki 
ketertarikan pada konten seputar vegan. Baik mengenai makanan vegan, informasi seputar nutrisi makanan vegan, manfaat vegan bagi kesehatan dan lingkungan, dan sedikit mengenai etika terhadap sesama makhluk hidup yang masih belum begitu dibicarakan.

Setelah beberapa waktu menjadi vegan influencer, para informan sudah terbilang konsisten dalam mengunggah konten dan sudah menemukan ciri khas pada setiap unggahannya. Hal ini ditunjukkan melalui berbagai cara, misalnya penataan feeds, tone pada photo editing, penulisan caption, ataupun cara informan dalam melakukan pengambilan foto ataupun video. Pada bagian ini, informan sudah dikenal sebagai vegan influencer sehingga penawaran kerjasama yang datang pun seringkali berkaitan dengan produk vegan baik itu kerjasama untuk promosi, endorsement, ataupun undangan untuk menjadi narasumber pada webinar seputar vegan. Promosi produk dapat membantu influencer membuat brandnya sendiri melalui image yang mereka buat (Jurj, 2019). Maka dari itu personal branding dan promosi produk berjalan secara beriringan dan berhubungan satu sama lain

Informan memiliki perencanaan tersendiri untuk setiap postingannya agar terbentuk ciri khas yang dapat menjadi pembeda antara sesama vegan influencer dan memperlihatkan bagaimana pemaknaan atau advokasi vegan oleh vegan influencer mulai dari kesehatan, lingkungan, etika, atau makanan. Beberapa fitur Instagram dalam post yang selalu digunakan oleh informan adalah caption, hashtag, dan kolom komentar. Caption digunakan oleh informan untuk menuliskan deskripsi dari foto ataupun video yang diunggahnya, seperti misalnya untuk menggambarkan rasa dari maknaan vegan, resep makanan, manfaat dari gaya hidup vegan, dll. Caption merupakan hal penting bagi para pengguna, karena sulit untuk memberikan impresi dengan tepat sesuai dengan apa yang ada di otak individu jika hanya dengan menggunakan representasi visual seperti foto (Maike van't Laar, 2017). Pada unggahan mengenai makanan vegan, makanan vegan masih dirasa identik dengan menu sayur hijau saja. 


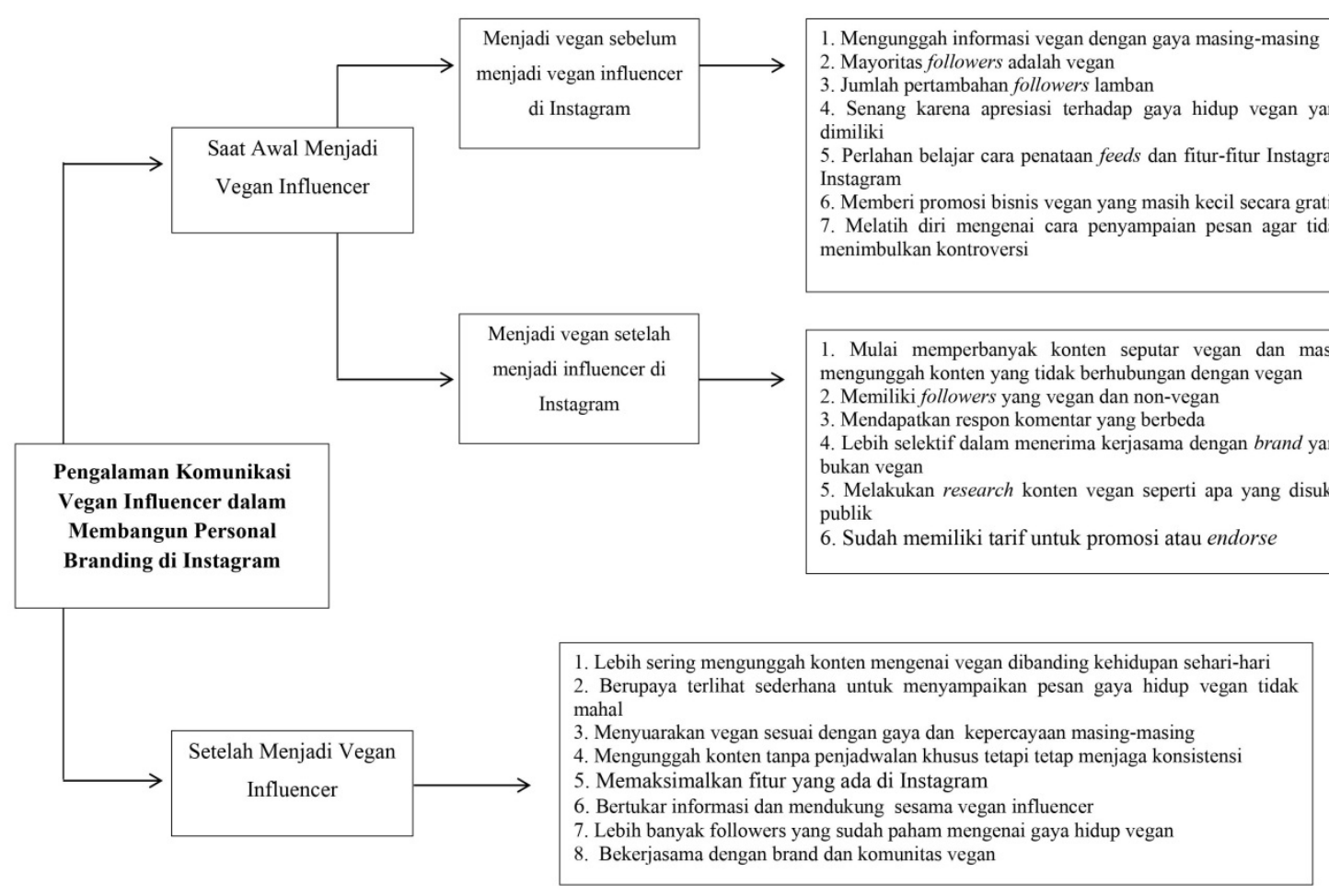

\section{Model 1.2 Pengalaman Komunikasi Vegan Influencer dalam Membangun Personal branding di Instagram} SIMPULAN

Berdasarkan hasil penelitian yang telah dikemukakan pada bab sebelumnya, dapat ditarik kesimpulan atas penelitian "Personal branding Vegan Influencer dalam Membangun Personal branding di Instagram" sebagai berikut,

Gaya hidup vegan sudah lebih dari sekedar pola makan saja tetapi juga mengenai gaya hidup yang diasosiasikan dengan nutrisi dan kesehatan, pemeliharaan lingkungan, dan etika terhadap makhluk hidup. Berkenaan dengan memberikan gambaran akurat seputar vegan, penting halnya untuk mengurangi dan menghilangkan stereotip dan mitos negatif yang tidak berdasar mengenai vegan dengan cara memberikan cerita dan kepercyaan mereka mengenai vegan yang tidak bersifat bias.

Ada berbagai motif vegan influencer dalam membangun personal branding di Instagram seperti dikarenakan jumlah vegan influencer Indonesia di Instagram yang masih sedikit, terinspirasi oleh vegan influencer dari luar Indonesia dan kesenangan medokumentasikan gaya hidup vegan dalam kehidupan sehari-hari, memberi informasi seputar vegan, mempengaruhi orang lain untuk menjadi vegan, menjaga kesehatan diri, mendapat endorsement dan materi, dan eksistensi. Motif-motif ini menjadi alasan para informan sampai saat ini bertahan menjadi seorang vegan influencer.

Para vegan influencer juga mengalami berbagai pengalaman komunikasi dalam membangun personal branding di Instagramnya. Saat awal menjadi vegan influencer di Instagram, informan mulai fokus membuat konten seputar vegan dan membentuk audiens di Instagram, hingga setelah beberapa waktu menjadi vegan influencer, informan melakukan 
konsistensi dan repetisi dalam pembuatan konten, menunjukkan ciri khas masing-masing, serta memaksimalkan fitur yang ditawarkan oleh Instagram.

\section{UCAPAN TERIMA KASIH}

Penulis mengucapkan terima kasih untuk 10 narasumber yang bersedia memberi informasi dan meluangkan waktunya untuk penyusunan artikel ilmiah ini. Penulis juga mengucapkan terima kasih kepada redaksi Jurnal Avant Garde dan reviewer atas masukan dan saran yang diberikan. Penulis juga mengucapkan terima kasih kepada semua pihak yang membantu dalam penyusunan artikel ilmiah ini.

\section{DAFTAR PUSTAKA}

Anshari, F. (2013). Komunikasi Politik di Era Media Sosial Faridhian Anshari Staff Pengajar STT PLN Jakarta. Jurnal Komunikasi, 8(1), 91-101.

http://dosen.univpancasila.ac.id/dosenfile/7014211002154994371612February2019.pdf

Ardianti, D. (2018). Penggunaan Caption Berbahasa Inggris di Instagram Sebagai Budaya Populer. Commits.

Arruda, W., \& Dixson, K. (2007). Career Distinction: Stand Out by Building Your Brand. John Wiley \& Sons, Inc.

Chang, C. Y. (2014). Visualizing brand personality and personal branding. 65-71. https://doi.org/10.17077/etd.8y3v071r

Christopher, A., Bartkowski, J., \& Haverda, T. (2018). Portraits of Veganism: A Comparative Discourse Analysis of a Second-Order Subculture. Societies.

Christopher, A., Bartkowski, J., \& Haverda, T. (2018). Portraits of Veganism: A Comparative Discourse Analysis of a Second-Order Subculture. Societies.

EAT-Lancet. (2019). Healthy diets from sustainable food systems. Food Planet Health.

Greger, M. (2016). About NutritionFacts.org. Nutrition Facts. https://nutritionfacts.org/about/ Hakim, A. Z., Hafiar, H., Puspitasari, L., Studi, P., Hubungan, I., Komunikasi, F. I., \& Padjadjaran, U. (2017). Personal branding of Homeschooling Teacher (Pengalaman Komunikasi Guru Homeschooling). Eduutech, 16(2), 122-137.

Harper, A. B. (2012). Taking food public: Redefining foodways in a changing world,. Jallinoja, P., Vinnari, M., \& Niva, M. (2018). Veganism and Plant-Based Eating: Analysis of Interplay between Discursive Strategies and Lifestyle Political Consumerism. https://doi.org/10.1093/oxfordhb/9780190629038.013.52

Johnston, O., \& Goodman, M. K. (2015). Spectacular Foodscapes: Food Celebrities and the Politics of Lifestyle Mediation in an Age of Inequality. Food Culture and Society An International Journal of Multidisciplinary Research.

Jurj, A. (2019). Insta-story for Personal branding and Product Promotion. Politehnica Graduate Student Journal of Communication. 4(1), 43-50.

Kuswarno, E. (2009). Metode Penelitian Komunikasi Fenomenologi. In Bandung: Widya Padjadjaran.

Mahdia, A. (2018). Pengaruh Konten Influencer di Media Sosial Terhadap Kesejahteraan Psikologis Remaja Akhir. Fakultas Psikologi Universitas Gunadarma, 11(2), 172-179. 
https://doi.org/10.35760/psi.2018.v11i2.2262

Maike van't Laar. (2017). The Self-Presentation of Vegans on Instagram Using Visual Content to Brand Oneself Within the Vegan Online Community. BA Eindwerkstuk: Media En Cultuur.

Mariezka, F. I., Hafiar, H., \& Yustikasari, Y. (2018). Pemaknaan Profesi Beauty Vlogger Melalui Pengalaman Komunikasi. Nyimak: Journal of Communication, 2(2), 95. https://doi.org/10.31000/nyimak.v2i2.920

Maslow, A. (2013). Motivasi dan Kepribadian (Teori Motivasi dengan Pendekatan Hierarki Kebutuhan Manusia). PT. PBP.

Maudia, F., Hafiar, H., \& Sani, A. (2018). Konstruksi Makna Reputasi Digital Melalui Perspektif Penyiar Radio. Profetik: Jurnal Komunikasi, 11(1), 54. https://doi.org/10.14421/pjk.v11i1.1351

McNally, D., \& Speak, K. D. (2004). Be Your Own Brand: Resep Jitu Meraih Personal Brand yang Unggul. Gramedia Pustaka Utama.

Mudrikah, I. M. (2020). Political Branding Politisi Perempuan di Instagram : Kasus Pada Tsamara Amany Alatas. Jurnal Politikom Indonesiana, 5(2), 29-39.

https://doi.org/10.35706/jpi.v5i2

Mulyani, S. (2016). Sistem Informasi Manajemen. Abdi Sistematika.

Oliver, J. (2021). Most Vegetarian Friendly Country In The World. Global Vegetarian Index. https://www.wowshack.com/indonesia-vegetarian-friendly/

Rusmulyadi, R., \& Hafiar, H. (2018). Dekonstruksi Citra Politik Jokowi Dalam Media Sosial. PRofesi Humas : Jurnal Ilmiah Ilmu Hubungan Masyarakat, 3(1), 120.

https://doi.org/10.24198/prh.v3i1.16729

Sugiyono. (2013). Memahami Penelitian Kualitatif. Alfabeta.

Veron. (2016). From Seitan Bourguignon to Tofu Blanquette: popularizing veganism in France with food blogs. In Critical perspectives on veganism. Palgrave Macmillan, Cham.

Wilson, A. V. (2019). IG VEGAN: A critical analysis of the discourses around food, identity and responsibility from vegan Instagram influencers. Social Sciences., 85. http://edepot.wur.nl/475593 